\title{
CHRNA5 and CHRNA3 polymorphism and lung cancer susceptibility in Palestinian population
}

\author{
Basim Mohammad Ayesh ${ }^{1 *}$ (D) Rami Al-Masri ${ }^{2}$ and Abdalla Assaf Abed ${ }^{3}$
}

\begin{abstract}
Objective: The genetic polymorphism (rs16969968 in CHRNA5, and rs1051730 in CHRNA3 genes) were recently shown to be associated with risk of $L C$. The aim of this study is to elucidate whether they predispose Palestinian individuals to lung cancer, and how is this related to smoking.

Results: Frequency of the rs 16969968-A allele was significantly higher in the case group (36.7\%) than in normal controls (17.5\%; $P=0.022 ; O R=6.83$ for $A A$ and 2.81 for $A G$ genotypes). The frequency of rs 1051730-T allele was also significantly higher in the case group (46.7\%) than in the control group (22.5\%; $P=0.001 ; \mathrm{OR}=2.20$ for TC and 13.22 for TT genotypes). Frequency of rs 16969968-A allele was higher in smokers (29.1\%) than nonsmokers (15.7\%) regardless of lung cancer; similarly, frequency of rs 1051730-T allele was also higher in smokers than in smokers (46.7\% vs $22.5 \%$, respectively). The higher the proportion of the risk allele (rs16969968-A and rs1051730-T), the higher the mean number of daily consumed cigarettes $(P=0.006)$. Carrying rs 16969968-A and/or rs 1051730-T alleles results in an increased risk to lung cancer probably by increasing the individual's tendency for heavy smoking. The allelic frequency of the rs16969968-A and rs1051730-T alleles among normal Palestinian controls is similar to different populations worldwide.
\end{abstract}

Keywords: s16969968, rs1051730, Lung cancer, Gaza strip, ASP-PCR, CHRNA5, CHRNA3, nAChR

\section{Introduction}

Lung cancer (LC) has been, for decades, the leading cause of male cancer related death both in developing and developed countries [1]. Recently, it has surpassed breast cancer as the leading cause of cancer death in females in developed countries, probably because of the lately spread of tobacco epidemic in females [2]. Both active and passive smoking are well known risk factors for lung cancer [3-9]. Between 80 and $90 \%$ of lung cancer are attributed to smoking $[10,11]$. Nevertheless, the majority of smokers don't develop LC during their life, most likely as a result of genetic polymorphism. Research has pointed the role of the person's genetic makeup in growing his/her likelihood of becoming attached to cigarettes as well as in increasing susceptibility to lung cancer

\footnotetext{
*Correspondence: bm.ayesh@alaqsa.edu.ps

1 Department of Laboratory Medical Sciences, Alaqsa University, Gaza,

Palestine, P.O. Box 4051

Full list of author information is available at the end of the article
}

[12-15]. Independent genome-wide association studies (GWAS) identified two single nucleotide polymorphisms (SNPs) in the genes for nicotinic acetylcholine receptor (rs16969968 in CHRNA5, and rs1051730 in CHRNA3 genes) to be consistently associated with risk of LC [16, 17]. Those polymorphisms are most likely increasing the risk of LC via increasing the individual's dependence to nicotine [18-22].

About $22.5 \%$ of Palestinian individuals ( $\geq 18$ years) are smokers [23]. LC is overall the third leading cause of death (9.8\% of reported cases), and is one of the major causes of morbidity among Palestinian population [24]. Therefore, in this study we aimed at determining the frequency of the SNPs (rs16969968 in CHRNA5, and rs1051730 in CHRNA3) and elucidating their possible role in risk for nicotine dependence and lung cancer among the Palestinian population. 


\section{Main text \\ Methods \\ Study design and population}

The present study is a case control study with convenience sample. Cases were recruited from all LC patients managed in the oncology departments of $\mathrm{Al}$ Shifa Hospital $(n=17)$ and European Gaza Hospital $(n=13)$ during the period from February 2014 to June 2014. Patients were excluded if their LC was a metastasis originating from other organs. The diagnosis of lung cancer was previously confirmed by the diagnostic tools available in the managing hospitals. The majority of cases were males (93.3\% males and $6.7 \%$ females). The mean age of lung cancer cases was $61.4 \pm 9.1$ years (range 45-80 years).

The control group comprised 60 participants (30 smoker and 30 nonsmokers) matched to the cases in gender $(71.7 \%$ males and $8.3 \%$ females) and age (mean $=60.4 \pm 7.9$ years; range $43-80$ years).

\section{Sample collection and genomic DNA extraction}

About $5 \mathrm{ml}$ peripheral blood were collected from each case and control in EDTA-anti-coagulated vacutainers. Genomic DNA was extracted from peripheral lymphocytes using the QIAamp DNA Blood Mini kit (Qiagen, Germany) according to the manufacturer instructions.

\section{Genotype determination with allele-specific primer (ASP) PCR} Allele-specific (AS) primers (Additional file 1) were designed using the Web-based Allele-Specific PCR assay (WASP) online software [25] and purchased from (Hylabs, Israel). Additional mismatches were intentionally introduced at the penultimate base of the AS primers to increase specificity as described earlier [26].

Two separate $20 \mu$ l-reactions were performed for each SNP, one for the wild-type allele and the second for the variant allele. All amplifications were carried out in the presence of $1 \times$ GoTaq Green Master Mix (Promega, USA), 50 ng genomic DNA, $0.5 \mu \mathrm{M}$ common sense primer and $0.5 \mu \mathrm{M}$ wild-type specific antisense or mutant-specific primers. The temperature profile for the SNP: rs16969968 included an initial denaturation at $95{ }^{\circ} \mathrm{C}$ for $5 \mathrm{~min}$, followed with 38 cycles of $95{ }^{\circ} \mathrm{C}$ for $30 \mathrm{~s}$, $58^{\circ} \mathrm{C}$ for $30 \mathrm{~s}$ and $72{ }^{\circ} \mathrm{C}$ for $45 \mathrm{~s}$. A final 10 min extension step was performed at $72{ }^{\circ} \mathrm{C}$. The temperature profile for the SNP: rs1051730 was the same except for annealing temperature which was performed at $59{ }^{\circ} \mathrm{C}$ for $30 \mathrm{~s}$. To validate the results, $10 \%$ randomly selected samples were re-genotyped and the results were concordant.

The amplification products were resolved by $2 \%$ agarose gel at $100 \mathrm{~V}$ for $50 \mathrm{~min}$ in $1 \times \mathrm{TBE}$ buffer. The gels
Table 1 Effect of minor alleles on smoking dependence

\begin{tabular}{lcc}
\hline Genotype & $\begin{array}{l}\text { No. cigarettes/day } \\
\text { (mean } \pm \text { SD) }\end{array}$ & P value \\
\hline CHRNA5 (c.1192G > A) rs16969968 & & \\
GG & $25.54 \pm 11.6$ & 0.006 \\
GA & $36.04 \pm 12.2$ & \\
AA & $40.0 \pm 15.81$ & \\
CHRNA3 (c.65C>T) rs1051730 & & \\
CC & $24.86 \pm 12.97$ & 0.006 \\
CT & $33.00 \pm 10.36$ & \\
TT & $39.17 \pm 15.62$ & \\
\hline
\end{tabular}

were stained with $0.5 \mu \mathrm{g} / \mu \mathrm{l}$ ethidium bromide and UVvisualized in a gel documentation system.

\section{Data analysis}

Data were collected from the patients including their age, gender, smoking status, number of cigarettes per day, type of cancer, years of smoking, period of quit smoking and others. The data was analyzed by the Statistical Package for the Social Sciences (SPSS; version 19). The student t test was applied to detect significant mean differences and the Pearson's $\chi^{2}$ test to detect distribution differences of categorical variables. Statistical significance was set at a threshold of $\mathrm{P}=0.05$ or less. The Hardy-Weinberg equilibrium was examined for the distribution of genotypes in each group using a goodness of fit $\chi^{2}$ test.

\section{Results ASP-PCR genotyping}

The ninety subjects enrolled in the study were successfully genotyped for the rs16969968 and rs1051730 by allelespecific primers PCR (Fig. 1). Repeated genotyping of a number of samples consistently gave concordant results.

\section{Distribution of CHRNA5 (c.1192G > A)/rs16969968}

The distribution of cases and controls by genotype of rs16969968 is shown in (Additional file 2). The alleles are in Hardy-Weinberg equilibrium $(P=0.6165)$, and the overall frequency of rs16969968-A is calculated to be $23.9 \%$ (Additional file 2). It is higher in the case group (36.7\%) than in the control group (17.5\%). Distribution of the genotypes among cases and controls is statistically significant $(P=0.022)$. Frequency of rs16969968AA homozygotes and rs16969968-GA heterozygotes is higher in cases than in controls. Homozygosity and heterozygosity for the minor allele increases susceptibility to lung cancer when compared to the wild type genotype $(\mathrm{OR}=6.83$ and 2.81, respectively; Additional file 3). 


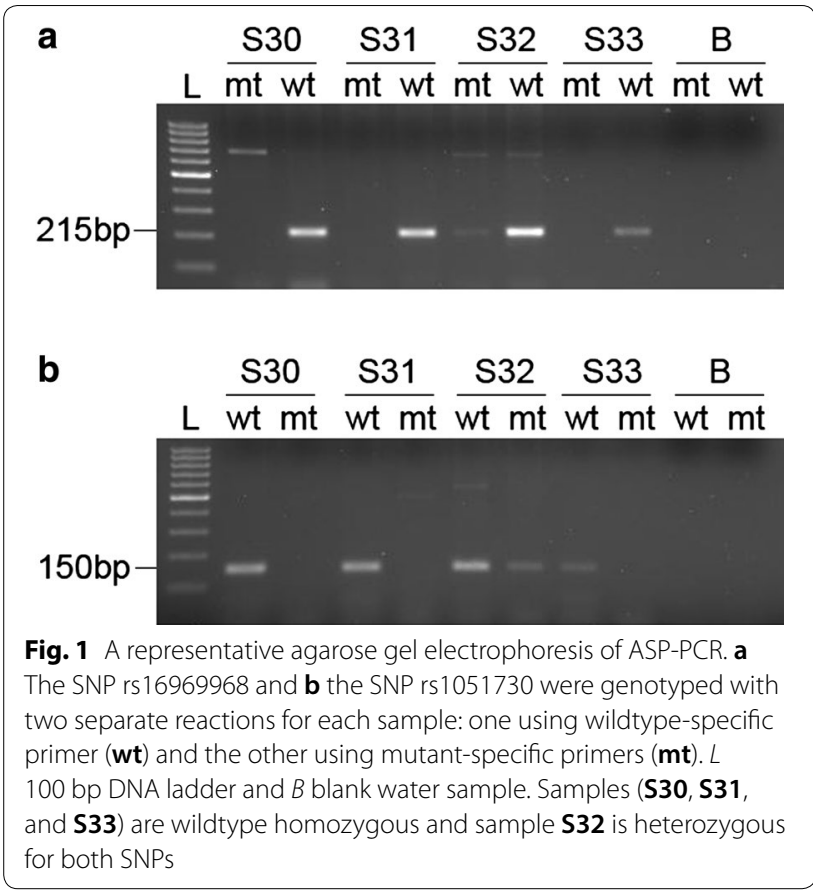

\section{Distribution of CHRNA3 (c.65C > T)/rs 1051730}

Alleles of rs1051730 are also in Hardy-Weinberg equilibrium $(P=0.887)$. The overall frequency of rs16969968-T allele is $31.1 \%$ (Additional file 2). The allelic frequency of the susceptibility allele is higher in the case group (46.7\%) than in the control group (22.5\%). Frequency of the rs1051730-TT and rs1051730-CT genotypes is significantly higher in cases than in controls $(P=0.001$; Additional file 2). Carriage of the rs1051730-T allele in a homozygous or heterozygous genotype increases the risk for lung cancer when compared to the wild type genotype $(\mathrm{OR}=3.05$; Additional file 3$)$.

\section{Smoking status}

Only four lung cancer cases were nonsmoker cases, while the rest 26 were smokers. Few patients have quitted smoking after being diagnosed and thus were considered smokers. The amount of cigarettes smoked per day by lung cancer patients and smoker controls was not significantly different $(P=0.823$; Additional file 4$)$. On the other hand, the average period of smoking was found to be significantly higher in lung cancer cases $(39.04 \pm 12.7$ years) compared to smoker controls (28.0 \pm 10.5 years $)(P=0.001$; Additional file 4$)$.

\section{Relationship between smoking and genotype in lung cancer}

Differences in distribution of the rs16969968 genotypes between the smoker cases and smoker controls was not statistically significant $(P=0.272$; Additional file 5).
Table 2 Effect of genotype on mean smoking duration

\begin{tabular}{lcc}
\hline & Duration (years) mean \pm SD & P value \\
\hline CHRNA5 (c.1192G > A) rs16969968 & \\
GG & $35.4 \pm 12.4$ & 0.402 \\
GA & $30.6 \pm 13.6$ & \\
AA & $31.8 \pm 10.7$ & \\
CHRNA3 (c.65C>T) rs1051730 & \\
CC & $35.8 \pm 13.1$ & \\
CT & $30.6 \pm 12.9$ & \\
TT & $35.8 \pm 10.3$ & \\
\hline
\end{tabular}

Analysis of statistical significance could not be applied to compare non-smoker case $(\mathrm{n}=4)$ and non-smoker control $(n=30)$ because of the small sample size. The allelic frequency of the rs16969968-A allele is higher in smokers $(29.1 \%)$ than nonsmokers $(15.7 \%)$, regardless of lung cancer.

On the other hand, differences in distribution of the rs1051730 genotypes between smoker cases and smoker controls was statistically significant $(P=0.015$; Additional file 5). Frequency of rs1051730-T allele is higher in smokers $(26.6 \%)$ than nonsmokers $(18.3 \%)$. regardless of lung cancer.

Table 1 shows that the higher the proportion of rs16969968-A allele or rs1051730-T allele, the higher the mean number of daily consumed cigarettes $(P=0.006$ for both alleles).

The average duration of smoking was not significantly different between the different genotypes of rs16969968 and rs1051730 genotypes $(P=0.402$ and 0.320 , respectively; Table 2).

\section{Discussion}

In this study, we have developed and applied an ASP-PCR technique for genotyping the rs16969968 and rs1051730 SNPs at the CHRNA5/CHRNA3 locus. The worldwide frequency of rs16969968-A allele ranges from $1 \%$ in certain populations such as African and Japanese to more than $47 \%$ in others such as European populations [27]. The frequency in our normal control individuals falls in the middle $17.5 \%$. The rs16969968-A allele frequency is higher in the case group (36.7\%). The distribution of rs16969968 genotypes among cases and controls is statistically significant $(P=0.022)$, supporting the potential role of rs16969968-A in risk of $\mathrm{LC}(\mathrm{OR}=6.83$ for rs16969968-AA and OR =2.81 for rs16969968-AG). Like previously reported data, this allele may be predisposing to LC independently from smoking [28-30].

The allelic frequency for the T-allele of the SNP rs1051730 in the control group is $22.5 \%$. The overall 
worldwide frequency of rs1051730-T allele is $16.8 \%$, ranging from $2.7 \%$ in east Asia to $47.7 \%$ in Iberian population of Spain [27]. Similar to rs16969968, frequency of rs1051730-T allele is higher in the case group, and the distribution of rs1051730 genotypes between cases and controls is statistically significant $(P=0.001)$. The rs1051730-TC and -TT genotypes seem to confer the individual susceptible to $\mathrm{LC}(\mathrm{OR}=2.20$ and 13.22 , respectively). These findings are parallel to previously published data which demonstrated that rs1051730-T allele is risk-conferring for the development of lung cancer in different ethnic groups [31-34]. These data also suggest an independent role for rs1051730-T allele in predisposition to lung cancer apart from smoking. The rs 1051730 polymorphism was suggested to modify susceptibility to lung cancer among Chinese Han population by a smoking-independent manner [35, 36]. It was also suggested to function as a genetic modifier for the risk of developing lung adenocarcinoma in nonsmoking Chinese females [37].

The postulation that both SNPs increase the risk of LC independently from smoking comes from Additional file 4 , in which the mean number of daily consumed cigarettes was not significantly different between the smoker cases and smoker controls $(P=0.823)$. Rather, the duration of smoking was far more important in predicting lung cancer risk ( $P=0.001$; Additional file 4$)$ [38-40]. In this regard, Table 2 shows that the genotype of both SNPs does not significantly influence the duration of smoking.

The allelic frequency of rs16969968-A and rs1051730-T susceptibility alleles was calculated in smokers and nonsmokers regardless of LC. The frequency of rs16969968A allele was higher in smokers (29.1\%) than nonsmokers (15.7\%). The frequency of rs1051730-T allele was also higher in smokers than in smokers $(46.7 \%$ vs. $22.5 \%$, respectively). Furthermore, Table 1 shows that the higher the proportion of the risk allele (rs16969968-A and rs1051730-T), the higher the mean number of daily consumed cigarettes $(P=0.006)$. Accordingly, we may consider homo- or heterozygosity for the rs16969968$\mathrm{A}$ and rs1051730-T allele predisposing for smoking dependence. In support of this assumption, carriers of the rs16969968-A allele were reported to have significantly higher serum nicotine levels, and to correlate with Fagerström test results for Nicotine Dependence [41]. Furthermore, higher smoking intensity was reported in rs1051730-CT heterozygote and rs1051730-TT homozygote smokers compared with wild-type smokers [42, 43].

Tobacco smoking increases the risk of at least 17 classes of human cancer probably by increasing the somatic mutation load [44]. Nicotine and other tobacco components may contribute to lung cancer by modifying the gene expression to induce epithelial to mesenchymal transition (EMT) [45-47]. Nicotine can also contribute to proliferation in LC through the activation of nicotinic acetylcholine receptors (nAChRs) [48]. Therefore, we may conclude that each of the rs16969968-A and rs1051730-T alleles increases the individual's dependence on tobacco smoking, which in turn confers him/her susceptible to LC. This conclusion supports previously reported association of rs16969968-A with LC risk largely via tobacco exposure [22, 49-51]. Lips, and colleagues demonstrated that association between rs16969968-A and LC risk was unchanged after adjusting for smoking $(\mathrm{OR}=1.30 \mathrm{VS}$ smoking adjusted $\mathrm{OR}=1.27$ ) [52]. Similar to our results, an increased nicotine level indicates an increased risk of LC with each additional copy of the rs 1051730 and rs16969968 risk allele [51, 53, 54]. A recent meta-analysis concluded that the rs16969968-A predicts delayed smoking cessation and an earlier age of lung cancer diagnosis [55].

In conclusion, carrying one or the other of the risk alleles rs16969968-A and rs1051730-T results in an increased risk to lung cancer probably by increasing the individual's tendency to smoke more and at an earlier age. The allelic frequency of the rs16969968-A and rs1051730-T alleles among normal Palestinian controls falls within the worldwide range in different populations.

\section{Limitations}

The main limitation of the present study is the small sample size, which limited our ability to detect moderate interactions especially in the stratified analyses. Larger studies are needed in the future to confirm our findings in the Palestinian population. In addition, lack of information and absence of properly organized patient record at the managing hospital limited access to the patients.

\section{Additional files}

Additional file 1. List of AS-primers for each SNP.

Additional file 2. Genotype distribution of the SNP rs16969968 and the SNP rs 1051730 among cases and controls.

Additional file 3. rs16969968 and rs1051730 genotypes and risk of lung cancer.

Additional file 4. Cigarettes consumption in smoker cases VS smoker controls.

Additional file 5. Genotype and minor allele distribution among smoker cases and controls.

Abbreviations

nAChR: nicotinic acetylcholine receptors; LC: lung cancer; GWAS: genomewide association studies; SNP: single nucleotide polymorphism; ASP-PCR: allele-specific primer PCR; OR: odds ratio.

Authors' contributions

BMA participated in the design of the study; designed and supervised on the molecular genetic studies and the statistical analysis. RA performed the 
molecular genetic studies and statistical analysis. BMA and RA drafted the final manuscript which was approved by all authors. AAA supervised on the theoretical and practical work. All authors read and approved the final manuscript.

\section{Author details}

${ }^{1}$ Department of Laboratory Medical Sciences, Alaqsa University, Gaza, Palestine, P.O. Box $4051{ }^{2}$ Central Laboratory, Ministry of Health, Gaza, Palestine.

${ }^{3}$ Biology Department, Islamic University of Gaza, Gaza, Palestine.

\section{Acknowledgements}

The authors wish to thank the medical staff in laboratory departments of European Gaza Hospital and Al-Shifa Hospital for their valuable help in collection of the blood samples and data.

\section{Competing interests}

The authors declare that they have no competing interests.

\section{Availability of data and materials}

The datasets used and/or analyzed during the current study are available from the corresponding author on reasonable request.

\section{Consent for publication}

Not applicable.

\section{Ethics approval and consent to participate}

The procedures of the study were approved by the ethical committee of the Palestinian health research council (No. PHRC/HC/51/13) according to the WMA Declaration of Helsinki-Ethical Principles for Medical Research Involving Human Subjects [56]. All enrolled participants gave their verbal consent after the study protocol was explained to them and approved by the institutional review board.

\section{Funding}

This research was funded by the Arab medical union, via the Palestinian health research counsel, and by the Palestinians Relief and Development Fund (Interpal)-UK supervised by Research \& Graduate Affairs at the Islamic University-Gaza.

\section{Publisher's Note}

Springer Nature remains neutral with regard to jurisdictional claims in published maps and institutional affiliations.

Received: 5 January 2018 Accepted: 20 March 2018

Published online: 02 April 2018

\section{References}

1. Ervik M, Lam F, Ferlay J, Mery L, Soerjomataram I, Bray F. Cancer fact sheets: lung cancer. 2016th ed. Lyon: International Agency for Research on Cancer; 2016.

2. Torre LA, Bray F, Siegel RL, Ferlay J, Lortet-Tieulent J, Jemal A. Global cancer statistics, 2012. CA Cancer J Clin. 2015;65:87-108.

3. Huang $T$, Chen $X$, Hong Q, Deng Z, Ma H, Xin Y, Fang Y, Ye H, Wang R, Zhang $\mathrm{C}$, et al. Meta-analyses of gene methylation and smoking behavior in non-small cell lung cancer patients. Sci Rep. 2015;5:8897.

4. Wells AJ. Lung cancer from passive smoking at work. Am J Public Health. 1998:88:1025-9.

5. Khuder SA. Effect of cigarette smoking on major histological types of lung cancer: a meta-analysis. Lung Cancer. 2001;31:139-48.

6. Boffetta P. Involuntary smoking and lung cancer. Scand J Work Environ Health. 2002;28(Suppl 2):30-40.

7. Armadans-Gil L, Vaque-Rafart J, Rossello J, Olona M, Alseda M. Cigarette smoking and male lung cancer risk with special regard to type of tobacco. Int J Epidemiol. 1999;28:614-9.

8. Gajalakshmi V, Hung RJ, Mathew A, Varghese C, Brennan P, Boffetta P. Tobacco smoking and chewing, alcohol drinking and lung cancer risk among men in southern India. Int J Cancer. 2003:107:441-7.

9. Wakai K, Inoue M, Mizoue T, Tanaka K, Tsuji I, Nagata C, Tsugane S. Tobacco smoking and lung cancer risk: an evaluation based on a systematic review of epidemiological evidence among the Japanese population. Jpn J Clin Oncol. 2006;36:309-24.

10. Obtel M, Nejjari C, Tachfouti N, Abda N, Belakhel L, Mathoulin-Pelissier $\mathrm{S}$. Estimating attributable fraction of lung cancer linked to smoking in Morocco. East Mediterr Health J. 2016;21:871-7.

11. Parkin DM. 2. Tobacco-attributable cancer burden in the UK in 2010. Br J Cancer. 2011;105(Suppl 2):S6-13.

12. Rothman N, Wacholder S, Caporaso NE, Garcia-Closas M, Buetow K, Fraumeni JF Jr. The use of common genetic polymorphisms to enhance the epidemiologic study of environmental carcinogens. Biochim Biophys Acta. 2001;1471:C1-10

13. Wain LV, Shrine N, Miller S, Jackson VE, Ntalla I, Soler Artigas M, Billington CK, Kheirallah AK, Allen R, Cook JP, et al. Novel insights into the genetics of smoking behaviour, lung function, and chronic obstructive pulmonary disease (UK BiLEVE): a genetic association study in UK Biobank. Lancet Respir Med. 2015;3:769-81.

14. Hancock DB, Eijgelsheim M, Wilk JB, Gharib SA, Loehr LR, Marciante KD, Franceschini N, van Durme YM, Chen TH, Barr RG, et al. Meta-analyses of genome-wide association studies identify multiple loci associated with pulmonary function. Nat Genet. 2010;42:45-52.

15. Wilk JB, Shrine NR, Loehr LR, Zhao JH, Manichaikul A, Lopez LM, Smith AV, Heckbert SR, Smolonska J, Tang W, et al. Genome-wide association studies identify CHRNA5/3 and HTR4 in the development of airflow obstruction. Am J Respir Crit Care Med. 2012;186:622-32.

16. Amos Cl, Wu X, Broderick P, Gorlov IP, Gu J, Eisen T, Dong Q, Zhang Q, Gu X, Vijayakrishnan J, et al. Genome-wide association scan of tag SNPs identifies a susceptibility locus for lung cancer at 15q25.1. Nat Genet. 2008;40:616-22.

17. Hung RJ, McKay JD, Gaborieau V, Boffetta P, Hashibe M, Zaridze D, Mukeria A, Szeszenia-Dabrowska N, Lissowska J, Rudnai P, et al. A susceptibility locus for lung cancer maps to nicotinic acetylcholine receptor subunit genes on 15q25. Nature. 2008:452:633-7.

18. Bierut LJ. Nicotine dependence and genetic variation in the nicotinic receptors. Drug Alcohol Depend. 2009;104(Suppl 1):S64-9.

19. Wang JC, Cruchaga C, Saccone NL, Bertelsen S, Liu P, Budde JP, Duan W, Fox L, Grucza RA, Kern J, et al. Risk for nicotine dependence and lung cancer is conferred by mRNA expression levels and amino acid change in CHRNA5. Hum Mol Genet. 2009:18:3125-35.

20. Stevens VL, Bierut LJ, Talbot JT, Wang JC, Sun J, Hinrichs AL, Thun MJ, Goate A, Calle EE. Nicotinic receptor gene variants influence susceptibility to heavy smoking. Cancer Epidemiol Biomarkers Prev. 2008;17:3517-25.

21. Le Marchand L, Derby KS, Murphy SE, Hecht SS, Hatsukami D, Carmella SG, Tiirikainen M, Wang H. Smokers with the CHRNA lung cancer-associated variants are exposed to higher levels of nicotine equivalents and a carcinogenic tobacco-specific nitrosamine. Cancer Res. 2008;68:9137-40.

22. Spitz MR, Amos Cl, Dong Q, Lin J, Wu X. The CHRNA5-A3 region on chromosome 15q24-25.1 is a risk factor both for nicotine dependence and for lung cancer. J Natl Cancer Inst. 2008;100:1552-6.

23. Palestinian Central Bureau of Statistics (PCBS). The situation of Smoking practice in the Palestinian Territory on the occasion of the "Word No Tobacco Day". http://www.pcbs.gov.ps/Portals/_pcbs/PressRelease/Fight _smok52011E.pdf. Accessed 23 Mar 2018.

24. PHIC. Health annual report. Gaza: Palestinian Ministry of Health; 2014

25. Wangkumhang P, Chaichoompu K, Ngamphiw C, Ruangrit U, Chanprasert J, Assawamakin A, Tongsima S. WASP: a web-based allele-specific PCR assay designing tool for detecting SNPs and mutations. BMC Genom. 2007;8:275

26. Little S. Amplification-refractory mutation system (ARMS) analysis of point mutations. Curr Protoc Hum Genet. 1995;7:9.8.1-12. https://doi. org/10.1002/0471142905.hg0908s07.

27. Ensembl. Ensembl release 86. 2016th ed. Cambridge:WTSI/EMBL-EBI; 2016.

28. Shiraishi K, Kohno T, Kunitoh H, Watanabe S, Goto K, Nishiwaki Y, Shimada Y, Hirose H, Saito I, Kuchiba A, et al. Contribution of nicotine acetylcholine receptor polymorphisms to lung cancer risk in a smoking-independent manner in the Japanese. Carcinogenesis. 2009:30:65-70.

29. Xu ZW, Wang GN, Dong ZZ, Li TH, Cao C, Jin YH. CHRNA5 rs 16969968 polymorphism association with risk of lung cancer-evidence from 17,962 lung cancer cases and 77,216 control subjects. Asian Pac J Cancer Prev. 2015;16:6685-90 
30. Ji X, Gui J, Han Y, Brennan P, Li Y, McKay J, Caporaso NE, Bertazzi PA, Landi MT, Amos Cl. The role of haplotype in 15q25.1 locus in lung cancer risk: results of scanning chromosome 15. Carcinogenesis. 2015;36:1275-83.

31. Sun H, Pan Y, He B, Deng Q, Ying H, Chen J, Liu X, Wang S. Different effects of the three polymorphisms on 15q25.1 onlung cancer risk: evidence from published literatures. J Cancer Res Ther. 2016;12:12-9.

32. Zhan P, Song Y. CHRNA3 rs1051730 polymorphism and lung cancer susceptibility in Asian population: a meta-analysis. Transl Lung Cancer Res. 2015;4:104-8

33. Gu M, Dong X, Zhang X, Wang X, Qi Y, Yu J, Niu W. Strong association between two polymorphisms on 15q25.1 and lung cancer risk: a metaanalysis. PLOS ONE. 2012;7:e37970.

34. Hu B, Huang Y, Yu RH, Mao HJ, Guan C, Zhao J. Quantitative assessment of the influence of common variations (rs8034191 and rs1051730) at 15q25 and lung cancer risk. Tumour Biol. 2014;35:2777-85.

35. Ren JH, Jin M, He WS, Liu CW, Jiang S, Chen WH, Yang KY, Wu G, Zhang T. Association between CHRNA3 rs1051730 genotype and lung cancer risk in Chinese Han population: a case-control study. J Huazhong Univ Sci Technolog Med Sci. 2013;33:897-901.

36. VanderWeele TJ, Asomaning K, Tchetgen Tchetgen EJ, Han Y, Spitz MR, Shete S, Wu X, Gaborieau V, Wang Y, McLaughlin J, et al. Genetic variants on 15q25.1, smoking, and lung cancer: an assessment of mediation and interaction. Am J Epidemiol. 2012;175:1013-20.

37. He P, Yang XX, He XQ, Chen J, Li FX, Gu X, Jiang JH, Liang HY, Yao GY, He JX. CHRNA3 polymorphism modifies lung adenocarcinoma risk in the Chinese Han population. Int J Mol Sci. 2014;15:5446-57.

38. Wiencke JK, Thurston SW, Kelsey KT, Varkonyi A, Wain JC, Mark EJ, Christiani DC. Early age at smoking initiation and tobacco carcinogen DNA damage in the lung. J Natl Cancer Inst. 1999;91:614-9.

39. Flanders WD, Lally CA, Zhu BP, Henley SJ, Thun MJ. Lung cancer mortality in relation to age, duration of smoking, and daily cigarette consumption: results from Cancer Prevention Study II. Cancer Res. 2003;63:6556-62.

40. Doll R, Peto R, Boreham J, Sutherland I. Mortality from cancer in relation to smoking: 50 years observations on British doctors. Br J Cancer. 2005;92:426-9.

41. Wojas-Krawczyk K, Krawczyk P, Biernacka B, Grzybek M, Kolodziej P, Kucharczyk T, Mlak R, Milanowski J. The polymorphism of the CHRNA5 gene and the strength of nicotine addiction in lung cancer and COPD patients. Eur J Cancer Prev. 2012;21:111-7.

42. Wium-Andersen MK, Orsted DD, Nordestgaard BG. Tobacco smoking is causally associated with antipsychotic medication use and schizophrenia, but not with antidepressant medication use or depression. Int J Epidemiol. 2015;44:566-77.

43. Rode L, Bojesen SE, Weischer M, Nordestgaard BG. High tobacco consumption is causally associated with increased all-cause mortality in a general population sample of 55,568 individuals, but not with short telomeres: a Mendelian randomization study. Int J Epidemiol. 2014;43:1473-83

44. Alexandrov LB, Ju YS, Haase K, Van Loo P, Martincorena I, Nik-Zainal S, Totoki Y, Fujimoto A, Nakagawa H, Shibata T, et al. Mutational signatures associated with tobacco smoking in human cancer. Science. 2016;354:618-22

45. Dasgupta P, Rizwani W, Pillai S, Kinkade R, Kovacs M, Rastogi S, Banerjee S, Carless M, Kim E, Coppola D, et al. Nicotine induces cell proliferation, invasion and epithelial-mesenchymal transition in a variety of human cancer cell lines. Int J Cancer. 2009;124:36-45.

46. Zou W, Zou Y, Zhao Z, Li B, Ran P. Nicotine-induced epithelial-mesenchymal transition via Wnt/beta-catenin signaling in human airway epithelial cells. Am J Physiol Lung Cell Mol Physiol. 2013:304:L199-209.

47. Vu T, Jin L, Datta PK. Effect of Cigarette Smoking on Epithelial to Mesenchymal Transition (EMT) in Lung Cancer. J Clin Med. 2016;5:44.

48. Dasgupta P, Rastogi S, Pillai S, Ordonez-Ercan D, Morris M, Haura E, Chellappan S. Nicotine induces cell proliferation by beta-arrestin-mediated activation of Src and Rb-Raf-1 pathways. J Clin Invest. 2006;1 16:2208-17.

49. Olfson E, Saccone NL, Johnson EO, Chen LS, Culverhouse R, Doheny K, Foltz SM, Fox L, Gogarten SM, Hartz S, et al. Rare, low frequency and common coding variants in CHRNA5 and their contribution to nicotine dependence in European and African Americans. Mol Psychiatry. 2016;21:601-7.

50. Chen LS, Baker T, Hung RJ, Horton A, Culverhouse R, Hartz S, Saccone N, Cheng I, Deng B, Han Y, et al. Genetic risk can be decreased: quitting smoking decreases and delays lung cancer for smokers with high and low CHRNA5 risk genotypes - a meta-analysis. EBioMedicine. 2016;11:219-26.

51. Munafo MR, Timofeeva MN, Morris RW, Prieto-Merino D, Sattar N, Brennan $\mathrm{P}$, Johnstone EC, Relton C, Johnson PC, Walther D, et al. Association between genetic variants on chromosome 15q25 locus and objective measures of tobacco exposure. J Natl Cancer Inst. 2012;104:740-8.

52. Lips EH, Gaborieau V, McKay JD, Chabrier A, Hung RJ, Boffetta P, Hashibe M, Zaridze D, Szeszenia-Dabrowska N, Lissowska J, et al. Association between a 15q25 gene variant, smoking quantity and tobacco-related cancers among 17,000 individuals. Int J Epidemiol. 2010;39:563-77.

53. Tseng TS, Park JY, Zabaleta J, Moody-Thomas S, Sothern MS, Chen T, Evans DE, Lin HY. Role of nicotine dependence on the relationship between variants in the nicotinic receptor genes and risk of lung adenocarcinoma. PLOS ONE. 2014;9:e107268.

54. Hallden S, Sjogren M, Hedblad B, Engstrom G, Hamrefors V, Manjer J, Melander O. Gene variance in the nicotinic receptor cluster (CHRNA5CHRNA3-CHRNB4) predicts death from cardiopulmonary disease and cancer in smokers. J Intern Med. 2016;279:388-98.

55. Chen LS, Hung RJ, Baker T, Horton A, Culverhouse R, Saccone N, Cheng I, Deng B, Han Y, Hansen HM, et al. CHRNA5 risk variant predicts delayed smoking cessation and earlier lung cancer diagnosis - a meta-analysis. JNCI J Natl Cancer Inst. 2015;107(5):djv100. https://doi.org/10.1093/jnci/ djv100.

56. WMA. World Medical Association Declaration of Helsinki: ethical principles for medical research involving human subjects. JAMA. 2013;310:2191-4.

\section{Submit your next manuscript to BioMed Central and we will help you at every step:}

- We accept pre-submission inquiries

- Our selector tool helps you to find the most relevant journal

- We provide round the clock customer support

- Convenient online submission

- Thorough peer review

- Inclusion in PubMed and all major indexing services

- Maximum visibility for your research

Submit your manuscript at www.biomedcentral.com/submit
BioMed Central 